\title{
Chicken-wing type congenital left atrial appendage aneurysm
}

\author{
Shu Yoshihara' ${ }^{1}$ Taku Yaegashi², Masaki Matsunaga ${ }^{3}$, Masaaki Naito \\ 1 Department of Diagnostic Radiology, Iwata City Hospital, Iwata, Japan \\ 2 Department of Radiological Technology, Iwata City Hospital, Iwata, Japan \\ 3 Department of Cardiology, Iwata City Hospital, Iwata, Japan
}

Correspondence to:

Shu Yoshihara, MD, Department of Diagnostic Radiology, Iwata City Hospital, 512-3 0okubo, Iwata, 438-8550, Japan, phone: +81538385000 , email: shuy@hospital.iwata.shizuoka.jp Received: December 10, 2020. Revision accepted: January 4, 2021. Published online: January 15, 2021. Kardiol Pol. 2021; 79 (2): 199-200 doi:10.33963/KP.15750 Copyright by the Author(s), 2021
A 48-year-old man was admitted to our institution because of congestive heart failure. Chest radiography taken when he entered primary school had indicated an abnormal cardiac silhouette. On admission, a resting 12-lead electrocardiogram showed atrial fibrillation with a heart rate of approximately $150 \mathrm{bpm}$. Chest radiography showed a convex bulge on the left heart border (FIGURE 1A). The plasma brain natriuretic peptide level was $1700 \mathrm{pg} / \mathrm{ml}$ (reference range, $0-19.5 \mathrm{pg} / \mathrm{ml}$ ) and the fibrin fragment $\mathrm{D}$-dimer level was $38.4 \mathrm{\mu g} / \mathrm{ml}$ (reference range, 0-1 $\mathrm{gg} / \mathrm{ml}$ ). Transthoracic echocardiography was performed, but was limited due to poor echogenicity. There was mild left ventricular systolic dysfunction, without significant valvular disease. Non-electrocardiogram-gated contrast-enhanced chest computed tomography showed a dilated left atrial appendage (LAA) filled with thrombus (FIGURE $1 B$ and $1 C$ ) extending in the anterior mediastinum (FIGURE 1B-1E). The morphology of the LAA was chicken-wing type, ${ }^{1}$ and it was $87 \mathrm{~mm}$ long and $44 \mathrm{~mm}$ wide. The LAA volume was $69 \mathrm{ml}$ and the LA volume was $143 \mathrm{ml}$. The LAA ostium dimensions were $35 \times 27 \mathrm{~mm}$, and its area was $7.3 \mathrm{~cm}^{2}$. Transesophageal echocardiography showed no valvular pathology, which resulted in a definitive diagnosis of congenital LAA aneurysm with thrombus (FIGURE 1F; Supplementary material, Video S1). LAA flow velocity was $18 \mathrm{~cm} / \mathrm{s}$. Because the patient refused surgical management of the LAA aneurysm, he was treated with oral warfarin.

LAA aneurysm is characterized by localized outpouching or diffuse enlargement of the LAA. It can be caused by congenital dysplasia of the pectinate muscle and related atrial muscle bands, or be secondary to mitral valve disease. In a study of 500 normal autopsy hearts, Veinot et $\mathrm{al}^{2}$ reported the size of normal LAAs in different age groups and sexes. The mean orifice diameter, body width, and length of the LAA in subjects aged 20 years or older were respectively $1.16,1.83$, and $2.59 \mathrm{~cm}$ for men, and 1.07 , 1.66 , and $2.53 \mathrm{~cm}$ for women. Although there is no clear consensus on a definition of LAA aneurysm, Aryal et $\mathrm{al}^{3}$ proposed that it could be defined as a LAA with dimensions larger than $2.7 \mathrm{~cm}$ in orifice diameter, $4.8 \mathrm{~cm}$ in body width, and $6.75 \mathrm{~cm}$ in length. Whether congenital or acquired, LAA aneurysms grow in size over several years and tend to become symptomatic with increasing risk of thromboembolism, so surgical treatment is often recommended even in asymptomatic patients. LAA aneurysm resection through a median sternotomy with a cardiopulmonary bypass is the most commonly reported operative approach. Less invasive approaches such as resection through a left lateral thoracotomy or resection with minimally invasive endoscopic techniques have also been reported. Since surgical LAA closure using the double-row suturing method during a minimally invasive mitral valve surgery performed through a right minithoracotomy has recently been shown to provide durable results, this technique may become an effective option for this pathology in the future. ${ }^{4}$ In patients with a large LAA aneurysm with atrial fibrillation and/or biatrial enlargement, a surgical atrial fibrillation ablation procedure should be performed, because resection of the large LAA aneurysm alone may leave dysmorphic atrial tissue that can predispose to atrial tachyarrhythmia. ${ }^{3}$ Although chicken-wing type LAA morphology has a relatively lower risk of thromboembolic events, aneurysmal 

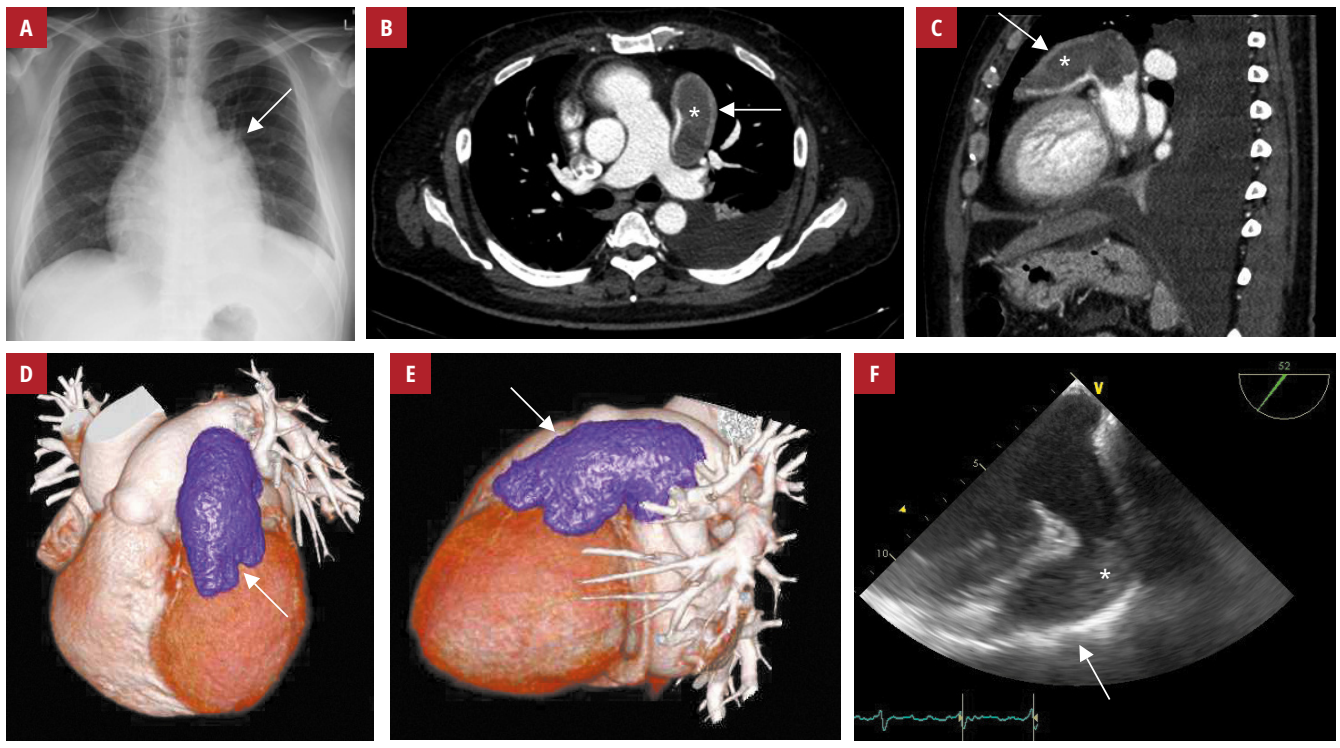

FIGURE 1 A - standing posteroanterior chest radiography showing a convex bulge on the left heart border (arrow);

B, C - multiplanar reconstruction axial (B) and sagittal (C) images of non-electrocardiogram-gated contrast-enhanced chest computed tomography showing left atrial appendage aneurysm (arrow) filled with thrombus (asterisk) extending in the anterior mediastinum; D, E - three-dimensional volume-rendered reconstruction images of non-electrocardiogram-gated contrast-enhanced chest computed tomography in the left anterior oblique view (D) and left lateral view (E) showing chicken-wing type left atrial appendage aneurysm (arrow); $\mathbf{F}$ - transesophageal echocardiography (mid-esophageal view at $52^{\circ}$ ) performed 7 days after chest computed tomography showing left atrial appendage aneurysm (arrow) with thrombus (asterisk).

dilatation of the LAA itself and a large LAA ostium in addition to the presence of atrial fibrillation would lead to stasis of blood and subsequent thrombus formation. ${ }^{5}$ Indeed, the presence of atrial fibrillation / flutter is reported to be the only significant predictor of LAA aneurysm-related thrombus formation and embolism. ${ }^{3}$

\section{SUPPLEMENTARY MATERIAL}

Supplementary material is available at www.mp.pl/kardiologiapolska.

\section{ARTICLE INFORMATION}

CONFLICT OF INTEREST None declared.

OPEN ACCESS This is an Open Access article distributed under the terms of the Creative Commons Attribution-NonCommercial-NoDerivatives $4.0 \mathrm{In}$ ternational License (CC BY-NC-ND 4.0), allowing third parties to download articles and share them with others, provided the original work is properly cited, not changed in any way, distributed under the same license, and used for noncommercial purposes only. For commercial use, please contact the journal office at kardiologiapolska@ptkardio.pl.

HOW TO CITE YoshiharaS, Yaegashi T, Matsunaga M, Naito M. Chicken-wing type congenital left atrial appendage aneurysm. Kardiol Pol. 2021; 79: 199-200. doi:10.33963/KP.15750

\section{REFERENCES}

1 Kimura T, Takatsuki S, Inagawa $\mathrm{K}$, et al. Anatomical characteristics of the left atrial appendage in cardiogenic stroke with low CHADS2 scores. Heart Rhythm. 2013; 10: 921-925.

2 Veinot J, Harrity P, Gentile F, et al. Anatomy of the normal left atrial appendage: a quantitative study of age-related changes in 500 autopsy hearts: implications for echocardiographic examination. Circulation. 1997; 96: 3112-3115.

3 Aryal M, Hakim F, Ghimire S, et al. Left atrial appendage aneurysm: a systematic review of 82 cases. Echocardiography. 2014; 31: 1312-1318.

4 Hirnle G, Lewkowicz J, Suwalski P, et al. Effectiveness of surgical left atrial appendage closure during minimally invasive mitral valve surgery. Kardiol Pol. 2020; 78: 1137-1141.

5 Biase L, Santangeli P, Anselmino M, et al. Does the left atrial appendage morphology correlate with the risk of stroke in patients with atrial fibrillation? Results from a multicenter study. J Am Coll Cardiol. 2012; 60: 531-538. 